\title{
Geleitwort der Herausgeber
}

Mit Gesetz vom 26. Juli 1918 über die Errichtung eines Reichsfinanzhofs und über die Reichsaufsicht für Zölle und Steuern wurden die Grundlagen für die Steuerrechtsprechung in Deutschland gelegt. Am 8. August 1918 beschloss der Bundesrat, dass der Reichsfinanzhof seinen Sitz in München hat. Der Reichsfinanzhof nahm dann schließlich seine Tätigkeit am 1. Oktober 1918 auf. Das 100-jährige Jubiläum der Steuerrechtsprechung in Deutschland ist Anlass, dem Bundesfinanzhof eine Festschrift zu widmen. Der Plan einer Festschrift ist in den Beratungen der Deutschen Steuerjuristischen Gesellschaft e.V. (DStJG) gereift. Als Herausgeber dieses Werkes haben sich Klaus-Dieter Drüen als Vorsitzender des Vorstands der DStJG, Johanna Hey als (damalige) Vorsitzende des Wissenschaftlichen Beirats der DStJG und der Präsident des Bundesfinanzhofs Rudolf Mellinghoff als Vorstandsmitglied der DStJG verbunden.

Reichsfinanzhof und Bundesfinanzhof sind im Lauf der letzten 100 Jahre bereits zu verschieden Anlässen Festschriften gewidmet worden. Die Festschrift für den Bundesfinanzhof aus Anlass der 100. Wiederkehr der Gründung des höchsten Steuergerichts in Deutschland ist keine beliebige Zusammenstellung thematisch heterogener Beiträge zum Steuerrecht, sondern nach der Konzeption der Herausgeber ein umfassender und abgestimmter Gesamtüberblick über Entwicklung und Stand der Steuerrechtsprechung nach 100 Jahren finanzgerichtlichen Rechtsschutzes. Nicht das Rechtsgebiet als solches, sondern die Perspektive der Steuerrechtsprechung steht im Zentrum des Werkes. Nach einer einleitenden Geschichte des Rechtsschutzes im Steuerrecht behandelt diese Festschrift die dogmatischen Grundlagen der Rechtsprechung im Steuerrecht. Ein weiterer Abschnitt widmet sich dem Steuerrecht in der Gesamtrechtsordnung, wobei die Bezüge zum Verfassungsrecht, zur nationalen Rechts- und Wirtschaftsordnung, zum Unionsrecht und zum Internationalen Steuerrecht in den Blick genommen werden. Entwicklungslinien und Zukunftsfragen werden sodann zu einzelnen Bereichen des materiellen Steuerrechts aufgezeigt. Die beiden letzten Kapitel der Festschrift widmen sich dem Steuerverfahrensrecht und dem Rechtsschutz in Steuersachen.

Das Vorhaben eines thematisch abgestimmten und sich ergänzenden Gesamtüberblicks zur Steuerrechtsprechung beschneidet natürlich die übliche Freiheit der Autoren von Festschriften, individuell ein Thema auszuwählen und zu Ehren des Jubilars zu behandeln. Zu den Festschriften eigenen Zeitvorgaben, die das Erscheinen des Werks zum fixen Zeitpunkt gewährleisten, haben die Herausgeber auch die Gesamtkomposition, den Aufbau und die Einzelthemen der Beiträge vorgeben. Zur großen Freude der Herausgeber haben sich die Autoren auf diese Zumutungen eingelassen und das große Gesamtwerk zu 100 Jahren Steuerrechtsprechung gewagt. Dafür gebührt an dieser Stelle der herzliche Dank allen Autoren des Werkes. Der Kreis der Autoren setzt sich aus Richterinnen und Richtern der Finanzgerichtsbarkeit sowie Hochschullehrern und -lehrerinnen der Steuerrechtswissenschaft und der Betrieblichen Steuerlehre zusammen. Dabei ist die Schar der Autoren nicht auf Deutschland 
begrenzt. Richter und Wissenschaftler aus verschiedenen europäischen Staaten steuern eine nachbarschaftliche Außensicht auf die Steuerrechtsprechung in Deutschland bei. Die Verbindungslinien zur Rechtsprechung anderer Gerichte behandeln die Beiträge von Richtern des Bundesverfassungsgerichts und der deutschen Generalanwältin am Gerichtshof der Europäischen Union sowie aus den Reihen der weiteren obersten Gerichtshöfe des Bundes. Die Rücklaufquote von 100 \% der zugesagten Beiträge ist bei Festschriften keineswegs selbstverständlich und zeugt wie auch die hohe Qualität der Beiträge für die besondere Wertschätzung für den Bundesfinanzhof.

Neben dem Dank an alle Autoren nutzen die Herausgeber dieses Geleitwort auch, um ihren Dank dem Verlag Dr. Otto Schmidt auszusprechen. Unser Plan einer Festschrift wurde von Beginn an von Herrn Felix Hey und Herrn Thomas Fischer nach Kräften unterstützt. Besonderer Dank gilt Herrn Dominic Hüttenhoff, der diese Festschrift mit großem Einsatz und Umsicht betreut hat.

Die Herausgeber freuen sich dank des tatkräftigen Einsatzes der Autorenschaft und des Verlags, dem Gericht und der Steuerfachwelt ein Gesamtwerk vorlegen zu können, das die Steuerrechtsprechung spiegelt, reflektiert und hoffentlich auch befruchten wird. Es soll den seit Langem gepflegten Dialog zwischen Steuerrechtsprechung und Steuerrechtswissenschaft fortsetzen und seinen Zwischenstand nach 100 Jahren dokumentieren.

München und Köln, im August 2018

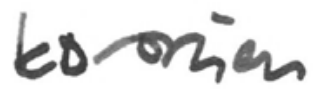

Klaus-Dieter Drüen

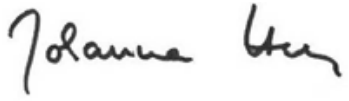

Johanna Hey

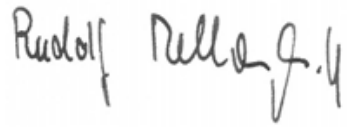

Rudolf Mellinghoff 